\title{
PRODUCCIÓN, COMUNICACIÓN, COMERCIO Y MONEDA EN LA LUSITANIA ROMANA: EL CASO DE LA VILLA ROMANA DE Clavellinas (Torremejía, BadAJOz)
}

Las obras de la A-66 (Autovía de Extremadura) descubrieron un gran número de yacimientos arqueológicos que fueron excavados y documentados en su totalidad. La Villa Romana de Clavellinas es uno de estos ejemplos. Excavada entre junio del 2001 y enero de 2002, aportó gran número de estructuras y de restos materiales, suficientes para considerarla como un centro productivo rural romano. A su vez, también se documentaron un gran número de monedas con una cronología del siglo I d.C. al IV d.C. La catalogación de estas monedas y la valoración conjunta de todos los elementos exhumados nos permiten aproximarnos a la economía rural de la Lusitania Romana.

Palabras Claves: Villa, economía rural romana, monedas, comercio, producción, calzada.

\section{Production, Connection, Trade, and Coin in lusitania: the Roman Village of Clavellina (Torremejía, BADAJOZ)}

When the A- 66 (Silver highway) was build, many archaeological ruins were discovered. These were documented and studied in totality. The Roman Villa of Clavellinas is one example which was excavated between July 2001 and January 2002. In this archaeological site many structures appeared and a lot of archaeological remains were found. Also, the archaeologists documented many coins dated between 1st and 4 th century BC. The study of these coins and the evaluation of these archaeological remains contribute to the understanding of the rural economy in the Roman Lusitania.

Key words: Villa, Roman rural economy, coins, trade, production, Roman road.

En la realización de las obras correspondientes a la construcción de la actual A-66 (Autovía de la Plata), la supervisión arqueológica necesaria para dicha ejecución, documentó en el tramo Mérida-Almendralejo Sur (P.K.16+480 a P.K 16+660) y término municipal de la localidad pacense de Torremejía, un gran número de restos cerámicos de época romana que fueron datados entre los ss. I d.C. al V d.C. Tras la paralización de la obra, notificación del hallazgo, solicitud de los permisos pertinentes para una intervención arqueológica y la autorización de ésta, se llevó a cabo una serie de sondeos mecánicos para valorar la entidad de los restos localizados y poder delimitar una superficie de excavación, que comprendió 10493 metros cuadrados. La empresa ARQUEPEC S.L. fue la contratada por parte de A.C.S., empresa adjudicataria de las obras de la autovía, para la realización de la excavación arqueológica, cuyos Arqueólogos Directores fueron Gemma Jurado Fresnadillo y Luis María Tirapu Carona a quienes agradecemos enormemente la autorización para realizar este estudio numismático y su correspondiente publicación. Por su parte, también agradezco a Guillermo Kurtz y a Beatriz Griñó Frontera, del Museo Arqueológico Provincial de Badajoz, su atención y cordialidad. 
La entidad de las estructuras documentadas, la identificación de una funcionalidad de tipo productivo en éstas, la inmensidad de restos cerámicos aparecidos, presencia monetal y la cercanía a la importante Vía de la Plata, fueron los factores que nos llevaron a intentar arrojar, a través de la numismática, nuevos datos para aproximarnos a la economía rural de época romana en la provincia romana de la Lusitania.

En este trabajo se lleva a cabo la presentación de la Villa romana de Clavellinas, yacimiento muy afectado a lo largo del siglo pasado por varias obras de carácter civil, pero que ha conservado ciertas estructuras que permiten identificar en ella un centro agropecuario de carácter productivo, con una vida que comienza a mediados del s. I d.C. y que finaliza, según el registro cerámico, en las postrimerías del s. V d.C.

Así, hemos decidido estructurar este presente trabajo de la siguiente manera: una primera parte destinada a explicar las diferentes partes que componen el yacimiento, junto a un comentario de los diferentes restos materiales documentados para poder contextualizar mejor la segunda parte, dedicada al estudio numismático de las monedas aparecidas. Finalizamos con una valoración socioeconómica de la Villa.

\section{LA VILLA}

La villa romana de Clavellinas recibe dicho nombre por haberse localizado en la finca homónima, respondiendo dicho yacimiento a las coordenadas UTM x:72277000, y: 4292400; a una distancia aproximada de 1,5 km al SO de la población de Torremejía (Badajoz).

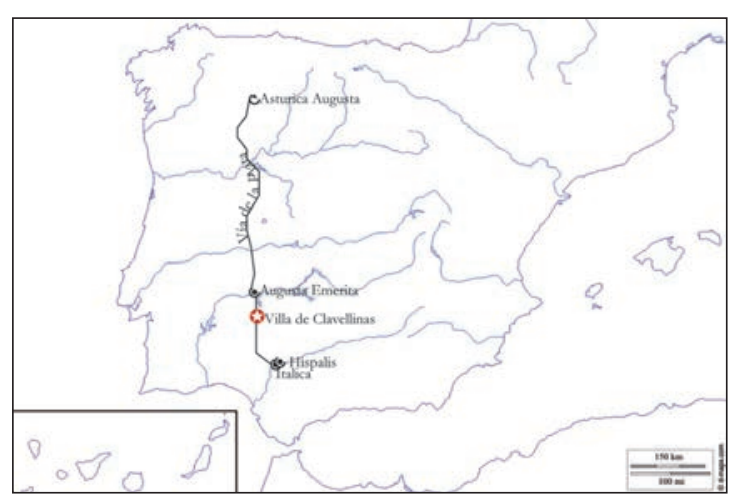

Fig. 1. Mapa donde se observa la ubicación de la Villa Romana de Clavellinas con respecto a la Vía de la Plata.
El yacimiento, por tanto, se encuentra en el centro de la amplia penillanura extremeña, correspondiéndose con la comarca de Tierra de Barros. Como el nombre de la comarca indica, esta zona presenta suelos de formación terciaria y cuaternaria compuestos principalmente de arcillas rojas y margas, muy favorables para el cultivo de la vid y del olivo (Rodríguez et al. 1988), explotaciones ya observadas en la villa de Clavellinas.

Por lo que respecta a su situación geográfica, el yacimiento se localiza en uno de los márgenes del trazado viario del camino Item ab ostio fluminis Aenae Emeritan usque (Roldán 1971), que en este mismo tramo compartía las vías X, con dirección a la ciudad de Hispalis, y la vía XXIII, con dirección a Italica, ya que ambas cruzaban la actual población de Torremejía (Rodríguez Martín 2008-2009). Por tanto, la villa se halla a unos $15 \mathrm{~km} \mathrm{li-}$ neales al S de la ciudad de Augusta Emerita, situación que condicionará el devenir de la villa, al encontrarse muy próxima a la zona periurbana de la ciudad (Sánchez Barrero 2000; 2011) y dentro de su territorio centuriado (Alonso et al. 1992-93; Ariño et al. 2004: 140 y ss.).

\section{DEFINICIÓN, ESTANCIAS Y MATERIALES}

Por lo que respecta a la villa, antes de efectuar su respectiva descripción e identificación, se debe de tener en cuenta el siguiente hándicap, y es que la excavación en extensión del yacimiento estuvo condicionada por el trayecto de la nueva vía y por el antiguo trazado de la $\mathrm{N}-630$, que se encuentra encima de gran parte de los restos. Como es evidente, este hecho restringe una visión global de la villa, pero no ha sido impedimento para poder valorarla como es debido.

La villa romana de Clavellinas es un centro de residencia y explotación rural de tipo diseminado (Fernández Castro 1982: 61-62; Smith 1997: 36-37), al presentar varias edificaciones domésticas o de carácter utilitario levantadas de manera independiente dentro del conjunto. Los autores se decantan por esta definición (Jurado y Tirapu 2006) al documentar tres sectores bien diferenciados por las evidencias industriales que han arrojado y que demuestran cómo este yacimiento ha ido creciendo y adaptándose a las necesidades socioeconómicas de cada momento. Debe recalcarse que no se ha identificado físicamente la pars urbana de la villa, por lo que todas las estructuras que se van a describir a continuación responden a la pars rustica. Como es evidente, esta ausencia 
estructural podría plantear la posibilidad de que nos encontráramos ante otro tipo de yacimiento más vinculado a la actividad económica, pero la inmensa cantidad de cerámicas de mesa, como terra sigillata y vasos de paredes finas, demuestran que en este yacimiento existió una zona de residencia, que probablemente haya sido destruida con la construcción de la N-630. A su vez, una lectura cronológica de todas las cerámicas documentas, permiten establecer una cronología que va desde el s. I d.C. a mediados del V d.C. para la ocupación de la villa. El hecho de que la excavación se haya centrado en la pars rustica es también bastante interesante, ya que desde hace muchos años, la mayoría de las intervenciones realizadas sobre este tipo de yacimientos se han centrado en la pars urbana, quedando al margen una realidad socio-económica bastante importante. Desafortunadamente no se nos han proporcionado los planos de la excavación, por ello hemos optado por realizar una descripción detallada de los sectores documentados.

El primer sector, denominado Sector 1000, presenta dos momentos y dos ámbitos. Se encuentra en la zona $\mathrm{O}$ del yacimiento y son las estructuras más castigadas por la N-630. Las evidencias más antiguas de este sector se corresponden con una serie de estructuras de tipo rupestre que se han identificado con las labores previas al proceso de transformación de la vid y del olivo. Cercanas a éstas, se documenta una fosa longitudinal de forma rectangular, de buena fábrica al presentar muros de opus vittatum, que seguramente estuviera destinada para el almacenamiento de vino y aceite, ya que se documentó un gran dolium embutido. Además, se observan evidencias de bóvedas y el uso del adobe, seguramente para aislar los productos de los cambios de temperatura. Adosada a esta zona se encontraba un lugar destinado al prensado de la uva y la aceituna. A mediados del s. II d.C. estas estructuras sufren un incendio y son destruidas y aprovechadas a partir del s. III para levantar otras nuevas, con una fábrica menos elaborada, destinadas a la misma actividad como demuestra la aparición de zonas de almacenaje y de producción, como son balsetas y varios lacus de gran capacidad, y que estarán funcionando hasta mediados del s. V d.C. como demuestra la cerámica aparecida.

Por lo que respecta al segundo sector, denominado Sector 2000, es definido por los arqueólogos como un conjunto de varios edificios independientes con plantas regulares e irregulares, donde se pudo observar en sus interiores una buena compartimentación del espacio. Estos habitáculos presentan una gran rusticidad como prueba la fábrica de sus muros, muy poco cuidada y un mampuesto con algunos elementos reutilizados. Por otra parte, no aparecieron evidencias suficientes como para identificar la utilidad de estos espacios, muy mal definidos en alguna de sus partes, y que seguramente estuvieran relacionados con la actividad agropecuaria, alguna función de tipo industrial o hábitat de las personas dedicadas al servicio de la villa.

Por último, el Sector 3000, se encuentra al otro lado de la N-630, y ha perdido la conexión con los anteriores sectores. Se documentan dos estructuras con distribución sencilla en la que se identifican tres habitaciones respectivamente que se han vinculado con actividades agropecuarias, aunque al igual que en las estructuras del sector anterior, no se descarta la posibilidad de encontrarse ante zonas de hábitat. De todas formas, este sector se encontró bastante arrasado y se creyó que sería el más alejado del centro neurálgico.

Por lo que respecta a los materiales, se han documentado un gran número de tipos cerámicos, comunes en los tres sectores. Así, debido a la escasa potencia estratigráfica del yacimiento, pues tenemos que advertir que el casi $100 \%$ de los materiales se recuperó en una amplia capa que conectaba el sustrato vegetal con las estructuras anteriores, vamos a establecer a través de los tipos cerámicos documentados una evolución cronológica de la villa, lectura que nos será de bastante utilidad parar realizar el comentario numismático posterior.

Las cerámicas más antiguas aparecidas son algunos fragmentos de terra sigillata sudgálica (Drag. 24/25), aunque los más numerosos son los de terra sigillata hispánica que nos contextualiza los primeros momentos de la villa de Clavellinas (ss. I y II d.C.) al haberse encontrado previas al incendio referido en el Sector 1000. Se han identificado formas como Drag.18, Drag. 29, Drag. 35 y Drag 36. Su procedencia se ha localizado en la zona septentrional de la Península, reconociéndose entre ellas las numerosas producciones de Tritium Magallum (Tricio, La Rioja), como atestiguan algunos sellos que hacen alusión a los talleres de Firmius y Sempronius. Según el informe de intervención, los fragmentos que coinciden con este tipo de formas son bastante numerosos, algo que no resulta extraño por ser Augusta Emerita un centro redistribuidor de estas cerámicas (Sáez y Sáez 1999), aunque son frecuentes en cualquier yacimiento hispano altoimperial (Romero y Ruiz 2005: 187). También se han documentado las formas Drag. 27, Drag. 15/17 y Drag. 37 que suelen ser identificase como los tipos nexo que unen las 
producciones del alto con el bajo imperio (Romero y Ruiz 2005: 187) y documentadas en el Sector 1000 en la colmatación de las estructuras productivas de los ss. I y II d.C.

Numerosas son también las cerámicas de paredes finas donde se han identificado el bol carenado (tipo Mayet XLIII), copas de pequeño tamaño (forma Mayet LIII) y vasos globulares (formas Mayet XLV y Mayet LI). Estas cerámicas de paredes finas, de producción emeritense, tienen una amplia distribución en la Lusitania y Baetica a través de la Vía de la Plata (Mínguez Morales 2005: 356) con una horquilla cronológica que empieza en el reinado de Claudio y que finaliza a finales del s. I d.C. (Rodríguez Martín 1996: 55). Por lo que respecta a las lucernas, se han registrado las formas Dress. $11 \mathrm{a} / \mathrm{b}$; Dress. 27 y Dress 28.

A partir del s. III d.C., y coincidente con la remodelación del sector 1000 , todas las formas anteriores empiezan a escasear a favor de multitud de fragmentos de terra sigillata africana del tipo A, C y D, de las cuales se han encontrado un gran número de formas que permiten establecer el momento del abandono del yacimiento. Así, las formas más recientes se corresponden con los tipos Hayes $9 a$, Hayes 9b, Hayes 26, Hayes 31 y Hayes 33 de terra sigillata africana del tipo A, que presentan fechas que oscilan entre mediados del s. II d.C. y mediados del s. III d.C. De las formas de terra sigillata africana del tipo C solo se ha identificado el tipo Hayes 76, el cual presenta una cronología que abarca gran parte del s. V d.C. Por último, entre los fragmentos de terra sigillata africana del tipo D se han identificado las formas Hayes 53b, Hayes 56, Hayes 61a, Hayes 61b, Hayes 63, Hayes 67, Hayes 76, Hayes 91a y Hayes 91b, los cuales son adscritos a la segunda mitad del s. IV d.C. y el s. V d.C. Por lo que respecta a las lucernas con una cronología similar, fue identificada la forma Dressel 30, cuya producción se fecha entre el s. III d.C. y el s. IV d.C. y el tipo Alt. VIII A, que es producida entre el s. IV d.C. y V d.C.

En lo concerniente a las demás cerámicas, como son las de uso común y cocina, se aprecian numerosos fragmentos y seguramente por cercanía procedan de los talleres emeritenses, aunque no es de extrañar que fueran producidos en la propia villa. Los restos de cerámicas de uso común y de cocina, al igual que todos los anteriores, atestiguan la presencia de una pars urbana, aunque no se haya localizado in situ. Por otra parte, en el Sector 1000 principalmente, pero presentes en los restantes, han aparecido gran número de fragmentos de dolia y ánforas de tipo vinario y oleario sobre todo a partir de la reforma del s. III, lo que probaría una reconversión de su capacidad productiva.
Aunque los restos materiales descritos de esta villa presentan un gran parecido con el registro cerámico de cualquier villa romana lusitana, sería interesante llevar a cabo un análisis de carácter tipológico mucho más profundo de los fragmentos de ánfora y de la terra sigillata, con tal de poder comprender con mayor profundidad la procedencia de los intercambios y conocer con mayor detalle los circuitos comerciales lusitanos.

\section{PRESENCIA DE MONEDAS}

$\mathrm{Al}$ igual que los restos cerámicos, las piezas monetales aparecidas en la villa de Clavellinas se encontraban en las primeras capas, por lo que hemos optado por valorar la masa monetaria desde un punto de vista diacrónico, al igual que los arqueólogos realizaron con las cerámicas anteriormente citadas. Por otra parte, y para desgracia nuestra, no se llevó a cabo un registro exhaustivo de la aparición de cada moneda en la excavación, información que nos hubiese sido muy útil para poder establecer relaciones entre la moneda en sí y las estructuras documentadas. Por tanto, valoraremos el registro numismático de manera genérica comparándolo en algunos casos con el registro cerámico, el cual nos aportará algunas pautas para entender la circulación monetaria del momento.

Debido a la heterogeneidad de la muestra, hemos decidido establecer una serie de grupos en función de las cronologías que hemos documentado, para favorecer así un comentario mucho más estructurado y menos denso (fig. 2).

\section{SIGLOS I Y II D.C.}

Corresponden a este periodo un total de 12 piezas, que representa $17,14 \%$ del material que sometemos a análisis. A este periodo, como es lógico, pertenece la moneda más antigua encontrada en la excavación, un as $C$. Cassius Celer acuñado el 16 a.C. (moneda $n^{\circ} 1$ ) bajo mandato de Augusto, y que posiblemente fuera perdida muchos años después de su acuñación debido al desgaste que presenta. Dentro de la misma dinastía Julio-Claudia, existen tres monedas (monedas $n^{\circ} 2,3$ y 4) que por metrología y estilo, posiblemente sean imitaciones hispanas de la moneda de Claudio I. Aunque tan solo hemos podido catalogar el tipo Minerva (RIC I $\left.n^{\circ} 110\right)$ en una de ellas, el tratamiento del retrato en el anverso de las dos restantes nos permite asociarlas a las citadas imitaciones, 
muy presentes en los yacimientos cercanos a la vía de la Plata (Blázquez Cerrato 2002: 281-284), como también en la propia Península Ibérica (Ripollès 2002) a raíz de la clausura de las cecas hispánicas. Sorprende que no hayan aparecido en el conjunto piezas acuñadas por la ceca de Augusta Emerita, debido a la cercanía espacial y temporal al yacimiento.

De la dinastía flavia disponemos de un total de cinco piezas. Cuatro de ellas fueron emitidas por Vespasiano, de las cuales dos ases presentan reversos frustros (monedas $n^{\circ} 5$ y 6) pero leyendas del anverso nos han permitido adscribirlas a este emperador. Las otras dos monedas son un sestercio acuñado en Lugdunum en el año 70 (moneda $\left.\mathrm{n}^{\circ} 7\right)$ y un denario emitido por la ceca de Roma en el 71 (moneda $\mathrm{n}^{\circ} 8$ ), ambas piezas muestran en el reverso la alegoría de la Pax romana. La moneda restante es un sestercio de Domiciano acuñado en Roma en el año 81 d.C. (moneda $\mathrm{n}^{\circ}$ 9).

Las últimas tres monedas englobadas en este amplio periodo de tiempo pertenecen al reinado de Adriano (un as [moneda $\mathrm{n}^{\circ} 10$ ] y dos sestercios [monedas $\left.\mathrm{n}^{\mathrm{o}} 11 \mathrm{y} 12\right]$ ), de las cuales solo hemos podido identificar una (RIC II $\mathrm{n}^{\circ}$ 637) debido a que las demás presentan reversos totalmente desgastados.

Tanto la moneda de época flavia como la antonina, reflejan el periodo de estabilidad política y social que caracteriza el último tercio del s. I d.C. y gran parte del s. II d.C. (Ripollès 2002: 204-205). La moneda circulante en Hispania, y en nuestro caso la fachada atlántica, es elevada debido a la prosperidad que se está viviendo en el Imperio (Blázquez Cerrato 2002: 290-291), lo que justifica la presencia de monedas de mayor valor como el denario de Vespasiano y el sestercio de Adriano; estos tipos de moneda fueron los que mayor representación tuvieron en los yacimientos del sur de la fachada atlántica durante la dinastía antonina (Arias Ferrer 2012: 194).

\section{SIGLO III}

Tan solo seis piezas, antoninianos, se encuentran acogidas a esta cronología, representando por tanto un $8,67 \%$ del total. Las piezas corresponden a los reinados de Galieno y a las imitaciones de las emisiones de Divo Claudio (año 270) acuñadas bajo el reinado de Aureliano (Ripollès 2002: 208-209).

Los antoninianos emitidos por Galieno pertenecen a tres emisiones diferentes, la primera acuñada en Roma a inicios de su reinado, el tipo Virtus Augustus (Moneda

\begin{tabular}{|c|c|c|c|c|c|}
\hline \multicolumn{5}{|c|}{ Distribución de moneda por siglos y emperadores. } \\
\hline \multicolumn{2}{|c|}{ Siglos I y II } & \multicolumn{2}{c|}{ Siglo III } & \multicolumn{2}{c|}{ Siglo IV } \\
\hline Emperador & $\mathbf{N}^{\mathbf{0}}$ & Emperador & $\mathbf{N}^{\mathbf{0}}$ & Emperador & $\mathbf{N}^{\mathbf{}}$ \\
\hline $\begin{array}{c}\text { Augusto (C. } \\
\text { Cassius Celer) }\end{array}$ & 1 & Galieno & 3 & Galerio & 1 \\
\hline Claudio I & 3 & $\begin{array}{c}\text { Aureliano } \\
\text { (Divo Claudio) }\end{array}$ & 4 & Constantino & 2 \\
\hline Vespasiano & 4 & & & Majencio & 1 \\
\hline Domiciano & 1 & & & Urbs Roma & 2 \\
\hline Adriano & 3 & & & Constantino II & 5 \\
\hline & & & & Constante & 5 \\
\hline & & & & Constancio II & 14 \\
\hline & & & & Decencio & 2 \\
\hline & & & & Juliano II & 1 \\
\hline & & & & Graciano & 5 \\
\hline & & & & Valentiniano II & 2 \\
\hline & & & & Teodosio I & 3 \\
\hline Total & 12 & Total & 7 & Total & 48 \\
\hline
\end{tabular}

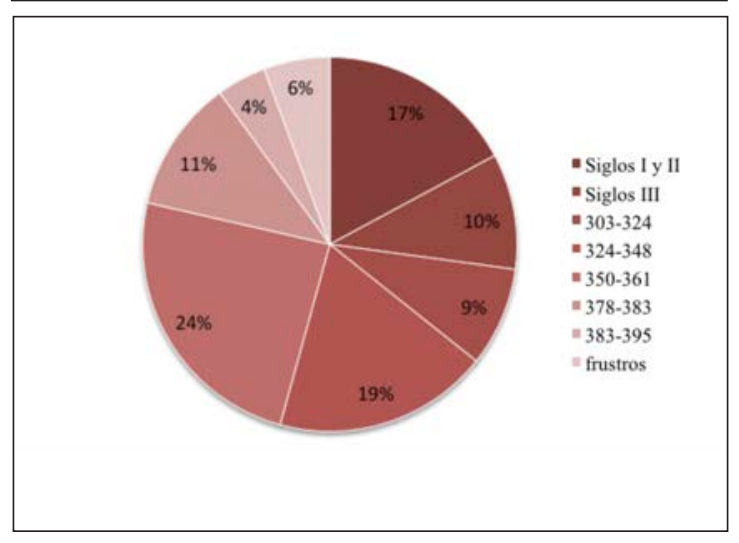

Fig. 2. Distribución del numerario por periodo cronológico.

$\left.\mathrm{n}^{\circ} 13\right)$ ( RIC $\mathrm{V}-\mathrm{A} \mathrm{n}^{\circ}$ 317), la segunda se corresponde con el tipo Aeternitas Augvsta acuñado en Mediolanum (moneda $\left.n^{\circ} 14\right)$ (RIC V-A no 373 ) y la tercera, que es la más reciente, el tipo Dianae mostrando un antílope (moneda $\left.\mathrm{n}^{\circ} 15\right)$ (RIC V-A n $\left.{ }^{\circ} 179\right)$, la cual fue acuñada en Roma en el año 267 d.C. Las tres piezas ejemplifican el aumento de la masa circulante que se observa durante el reinado de Galieno y que se ha podido constatar en la propia $\mathrm{Lu}-$ sitania (Da Silva 2008: 285). Se puede observar en estos tres ejemplos la reducción de plata que sufren los antoninianos en los últimos años del reinado de Galieno, ejemplo del grave deterioro que sufría el sistema monetario romano por estas fechas (Ripollès 2002: 207-208). 
Noé Conejo Delgado

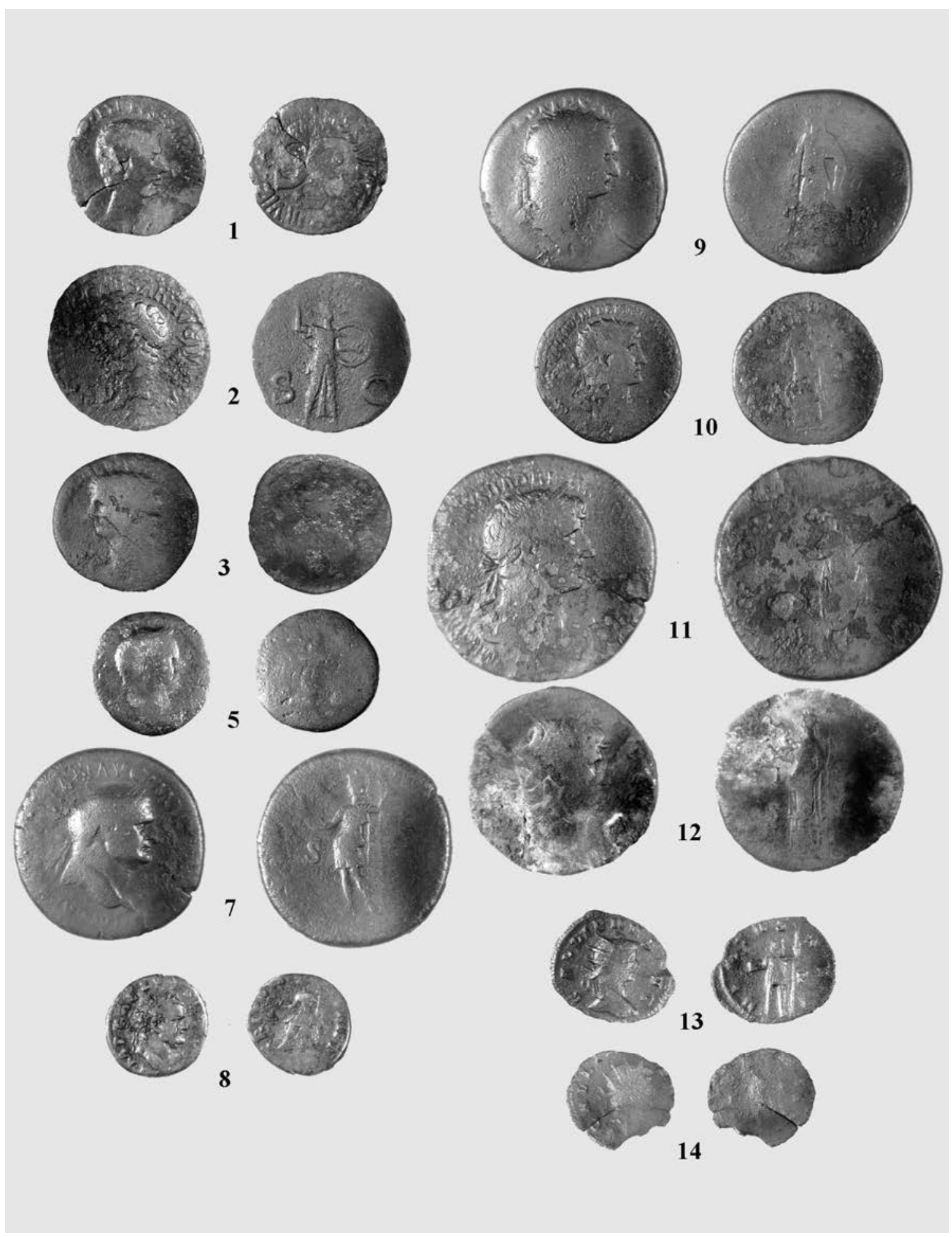

Fig. 3. Colección numismática de Clavellinas. Números de inventario 1 a 14. 


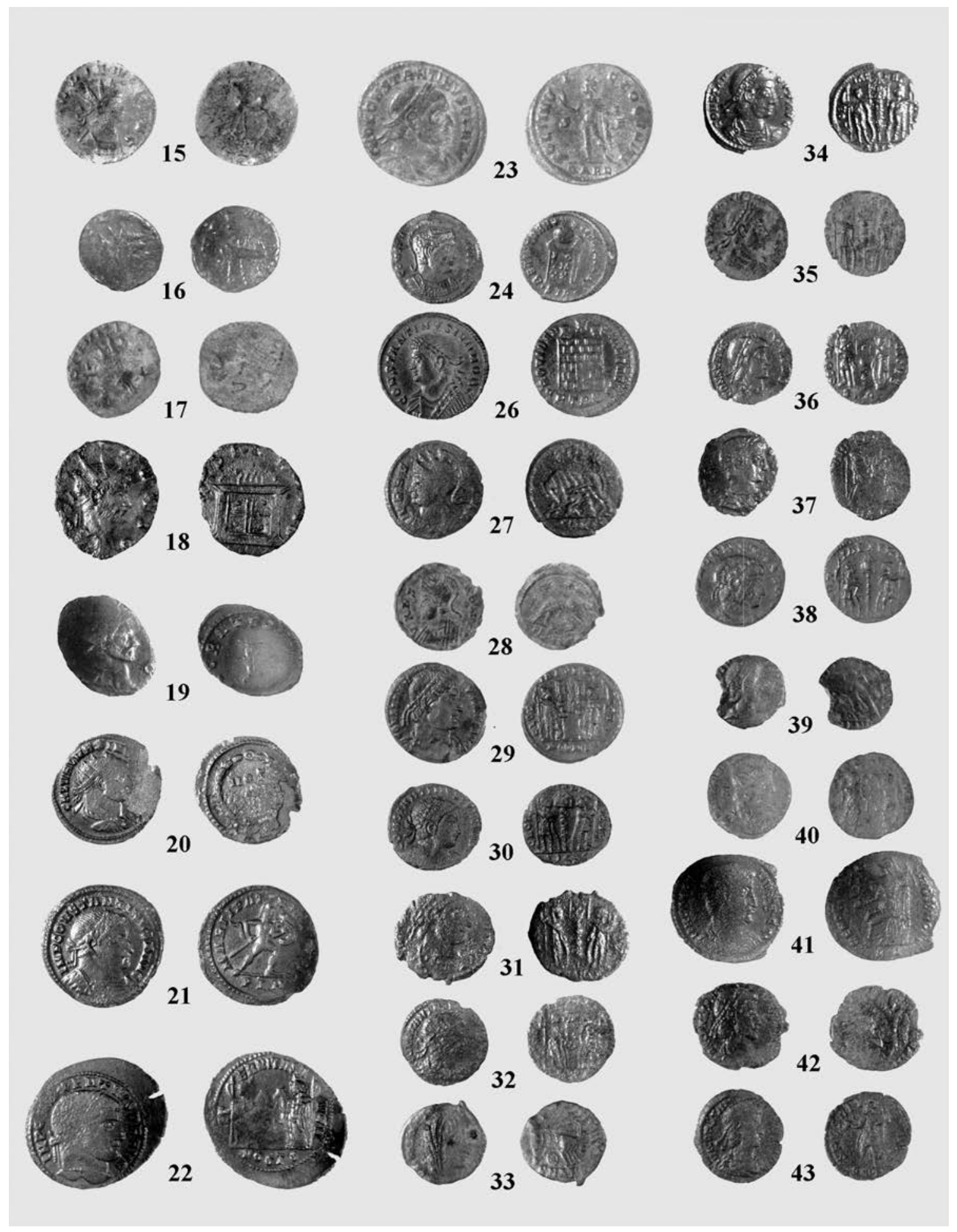

Fig. 4. Colección numismática de Clavellinas. Números de inventario 15 a 43. 


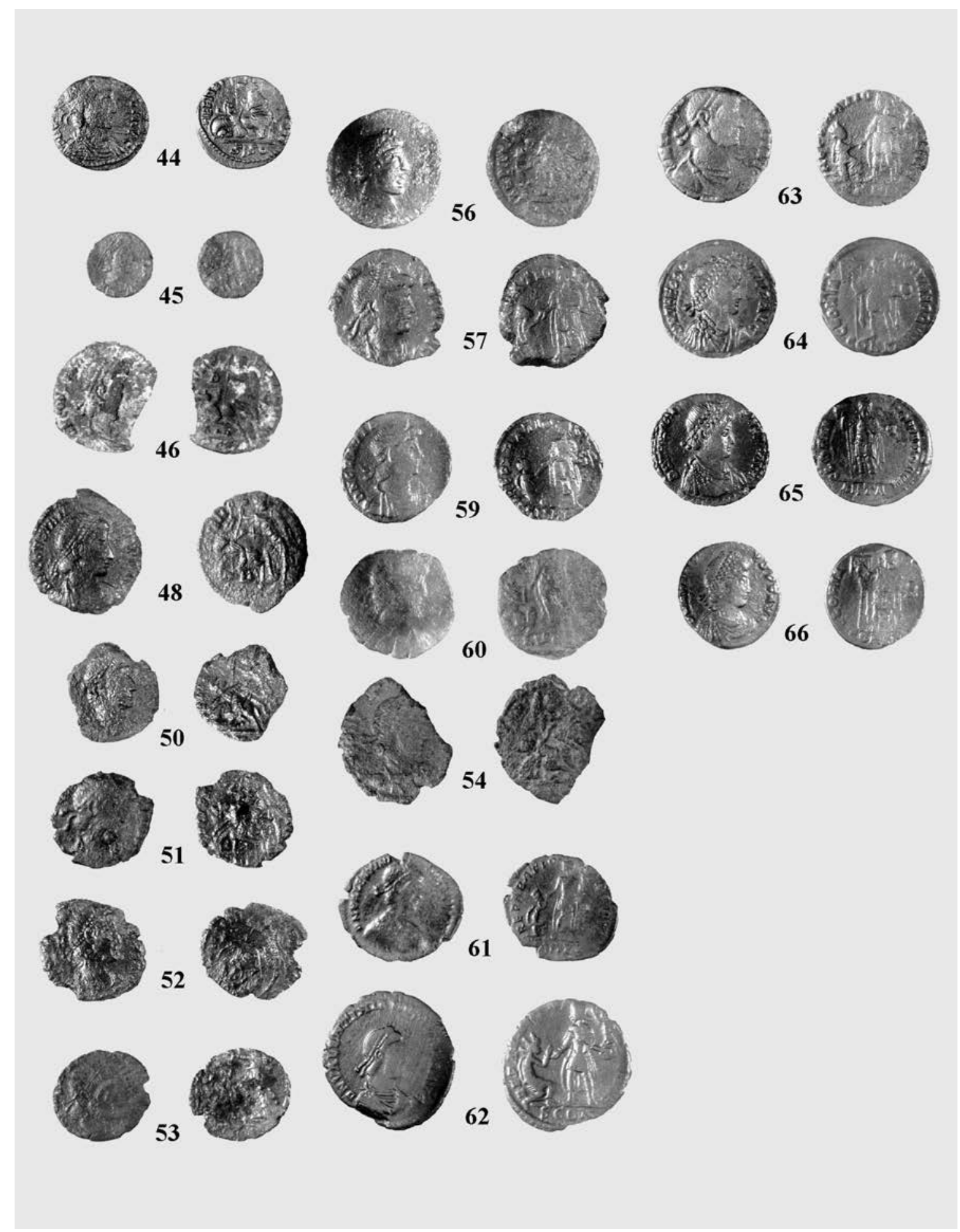

Fig. 5. Colección numismática de Clavellinas. Números de inventario 44 a 66. 
Los antoninianos del tipo Divo Claudio (monedas $\mathrm{n}^{\circ}$ $16,17,18$ y 19), son a nuestro juicio imitaciones hispanas debido a los pesos, la irregularidad de los cospeles y la tosquedad de los tipos. Como bien expone Ripollès (2002: 209) tendrán una gran circulación por la Península sin aún existir una explicación al porqué de estas imitaciones. En la Lusitania también tendrán una presencia significativa (Da Silva Ruivo 2008: 294 y ss).

\section{SIGLO IV}

Las monedas con cronologías enmarcadas en el s. IV son las más numerosas, un total de 48 piezas que representan el 66,57\% de la muestra y donde documentamos la presencia de 12 emperadores. Existe el hándicap de que muchas de las monedas que presentamos han sido catalogadas de manera aproximada, ya que hemos podido observar algún elemento que nos ha permitido atribuirlas a un emperador en concreto. De todas formas, hemos intentado acotar al máximo la catalogación para evitar posibles errores.

Las piezas más antiguas de este periodo corresponden a las novedades establecidas por la reforma de Diocleciano del año 294. Así, encontramos una moneda radiada de Galerio acuñada en Carthago en el año 303 (moneda $n^{\circ}$ 20), seguidas de varios follis acuñados en tiempos de Constantino y Majencio (moneda $\mathrm{n}^{\circ} 22$ ), donde se puede apreciar la paulatina disminución del peso teórico de este tipo de moneda, establecido por Diocleciano en 8,5 gr, encontrando alguna de hasta 2,20 gr, como la pieza número 25. Las monedas más numerosas son las acuñadas por Constantino (un total de cuatro), con cronologías que oscilan entre el 307 y el 320. Los tipos de reversos son los característicos, Marti Patri Propugnatori (moneda $\mathrm{n}^{\circ}$ 21), Soli Invicto Comiti (moneda $\left.\mathrm{n}^{\circ} 23\right)$, Beata Tranquilitas (moneda $\left.\mathrm{n}^{\circ} 24\right)$ y Vot $X X$ (moneda $\left.n^{\circ} 25\right)$. Las cecas identificadas en estos tipos son todas occidentales (Carthago, Ostia, Londinum, Arelate, Treveris, Ticinum), sorprendiéndonos la ausencia de piezas acuñadas en Roma, aunque se observa el predomino de cecas galas, como se ha documentado en los yacimientos coetáneos repartidos por la península Ibérica (Gurt 1985: 180; Blanco 1987: 165; Campo 1990: 29; Rodríguez Casanova 2002: 132).

Posteriormente a éstas se encuentran las que hemos englobado entre los años 324 al 348, emisiones conmemorativas (tres piezas) (monedas $\mathrm{n}^{\circ} 27,28$ y 33), Constantino II (monedas $\mathrm{n}^{\circ} 29,30,31$ y 32 ) y Constante I (monedas $\mathrm{n}^{\circ} 23,25,26,27,38$ ). Todas fueron emitidas antes y después de la reducción de pesos que se establece en el año 335 y que se mantuvo vigente hasta el año 348 , cuando se emitieron nuevos divisores (RIC VII 1966: 60; San Vicente 1999: 76 y ss.; San Vicente 2008: 623-624). Los tipos más representativos en este conjunto serán el Gloria Exercitus, que es el más numeroso junto al de Victoriae dd augg q nn que solo está presente con un ejemplar. Las emisiones conmemorativas son del tipo Urbs Roma con dos ejemplares y una acuñación póstuma de Constantino que aparece con cabeza velada. En cuanto a las cecas, debemos tener en cuenta que muchas de las monedas que se encuentran recogidas en esta horquilla temporal no conservan marca de ceca debido al acusado desgaste, pudiéndose identificar su emisión gracias a la lectura parcial de sus anversos. De todas formas, por estas fechas se han identificado monedas emitidas en Constantinopolis, Siscia y Heraclea, junto a otras acuñadas en Roma, Arelate y Lugdunum. Por tanto, se observa cómo empieza de manera paulatina a llegar numerario procedente de cecas orientales, como se ha podido ver en yacimientos como Conimbriga (Pereira et al. 1974: 250 y ss.), Italica (San Vicente 1999: 224) o La Olmeda (Campo 1990: 31), donde estas acuñaciones tendrán una representación secundaria.

Posteriormente al 348, documentamos dos tipos de acuñaciones. Por una parte dos monedas de Decencio (monedas 40 y 41), que siguen los parámetros establecidos por Magnencio (RIC VIII 1981: 61 y ss.; San Vicente 1999: 79-80). Por otra parte, se encuentran las acuñaciones Fel. Temp. Reparatio con el tipo falling horseman, las cuales empiezan a desarrollase a partir de la reforma del año 348. La gran mayoría de las piezas que disponemos en este periodo fueron emitidas tras la unificación del Imperio por parte de Constancio II (monedas $n^{\circ} 42-$ 54) tras la derrota de Magnencio entre el 350-353. Las monedas presentan pesos cercanos a 2,5 gr. y un diámetro inferior a $18 \mathrm{~mm}$ (Carson y Kent 1976: $\mathrm{n}^{\circ}$ 45-105), por lo que pueden responder a las emisiones posteriores de la reforma del año 357, al encontrarse pesos cercanos a 2,25 gr, que estarían ligados a la aparición de la M en el campo derecho del anverso (RIC VIII 1981: 65 y 70; San Vicente 1999: 82). Por su parte, según otros ejemplos de villae en Hispania, son el numerario más representado en este tipo de yacimiento (Chavarria 2007: 87 -88), producto sin duda del proceso inflacionario que está viviendo el Imperio y que se ha podido observar en Hispania con la llegada de bastante numerario hasta el 361, momento a 
partir del cual empezará a disminuir (Ripollès 2002: 211). También se ha documentado una moneda de Juliano II con estos mismos parámetros, emitida cuando aún era césar.

Debido a la falta de la marca de ceca en muchas de estas monedas, hemos decidido fecharlas con una cronología estimada del 355 al 361, mientras que para las piezas de las que sí disponemos marca, hemos optado por la cronología que aporta el RIC, similar a las anteriores. De Constancio II, además hemos documentado dos acuñaciones del tipo Spes Rei Publicae, una emitida en Arelate y otra sin marca (monedas $n^{\circ} 43$ y 47). Presentan pesos cercanos a 1,96 gr; siendo denominados ya como AE4 por algunos autores (Carson y Kent 1976: no 45-105), a quienes hemos seguido. En cuanto a las cecas, tan solo hemos podido identificar tres en todas las monedas del reinado de Constancio II, Constantinopolis y Siscia para el tipo primero y Arelate para el segundo.

Después de las monedas de estos reinados, encontramos cinco AE2 emitidos por Graciano entre el 378 y el 383 con el tipo de Reparatio Reipub (monedas $\mathrm{n}^{\circ} 56^{\prime}-59$ ) y que fueron creadas tras la muerte de Valente, de quien no hemos documentado moneda, pero sí de Valentiniano II (monedas $\mathrm{n}^{\circ} 61$ y 62), con las mismas características que las de Graciano. Constantinopolis, Aquileia y Lugdunum, son las cecas identificadas en estas seis monedas.

Los reinados más recientes documentados en el registro numismático de nuestra villa serán el de Teodosio I (379-395) (monedas $n^{\circ}$ 63, 64 y 65) y de Arcadio (383408) (moneda $n^{\circ} 66$ ), aunque éste sea emperador de la pars orientalis del Imperio. Disponemos de una moneda acuñada por Teodosio en la ceca de Nicomedia de los primeros años de su reinado, un AE2 que sigue los parámetros de la reforma de Graciano con el tipo Reparatio Reipub. Las demás piezas, dos, responden a los AE2 del tipo Gloria Romanorum, los cuales fueron acuñados en cecas orientales (Constantinopolis y Antioquia en nuestro caso), que tienen una presencia muy significativa en torno a la Vía de la Plata (Figerola 1999: 375) y que su circulación se dio entre el año del ascenso al trono por parte de Honorio, en el 393, y la muerte de Teodosio en el 395 (San Vicente 1999: 92-94; Cepeda 2000: 172174). Por lo que respecta a la moneda de Arcadio, presenta estos mismos parámetros.

Según Cepeda (2000: 175) a partir del s. V, y debido a la involución que sufren los territorios interiores de la Lusitania hacia formas económicas poco monetarias debido a una fuerte ruralización, en las villae, las necesidades monetarias son eventuales, registrándose una ausencia del uso de moneda de bronce en contextos rurales de Hispania.

\section{VALORACIÓN SOCIOECONÓMICA DE LA VILLA DE CLAVELLINAS}

En la villa romana de Clavellinas podemos establecer la confluencia de cuatro factores esenciales, los cuales nos permiten entender la importancia de la villa como centro productivo de la economía rural romana: producción, comercio, conexión viaria y moneda.

Durante muchos años, la presencia de moneda en las áreas rurales romanas ha pasado desapercibida a excepción de los trabajos planteados en su día por Bost (199293), quien denunciaba la escasez de estudios y algunas

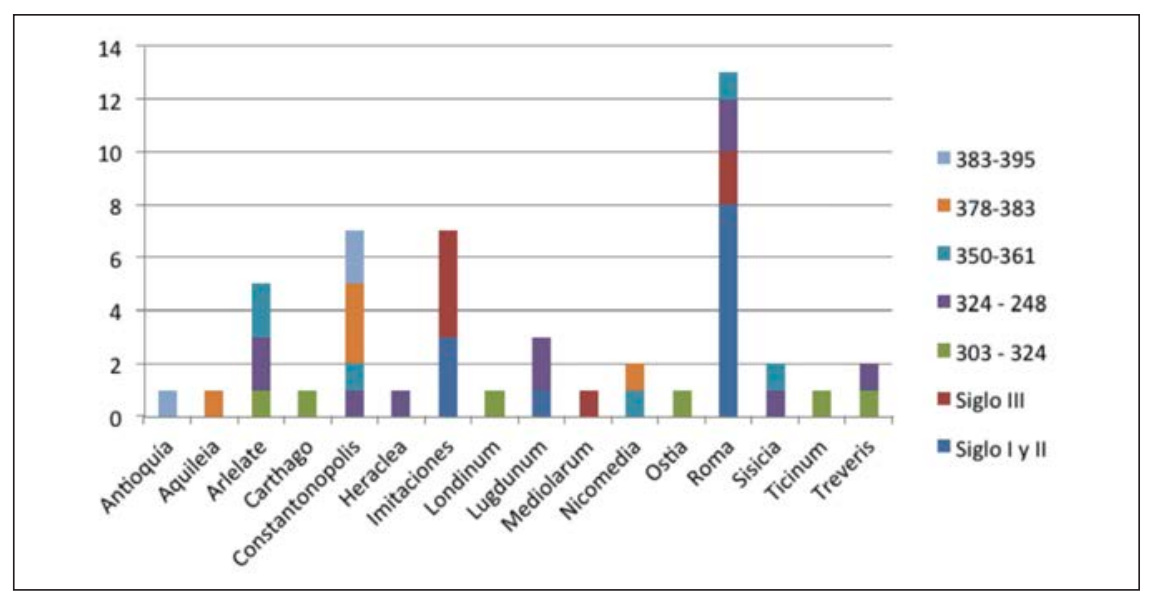

Fig. 6. Gráfico donde se establece la distribución cronológica de las cecas identificadas.. 
ideas que no tenían que ver con la realidad histórica. A su vez, Bost identificó en función de los hallazgos monetarios dos tipos de villae; por una parte, las villae que practicaban economías de mercado al documentar en sus excavaciones evidencias de intercambios entre los excedentes que ellos producían, fundamentalmente vino, aceite y cereal, e importaciones de productos de lujo o semi-lujo como las cerámicas foráneas, es decir, villae que tendrían un papel importante en circuitos comerciales amplios. Por otra parte estarían las villae practicantes de economías de subsistencia, las cuales estarían incluidas en circuitos comerciales cortos. Estas dos realidades condicionarán la presencia de monedas, según su opinión, por una sencilla asimilación, a más intercambios comerciales más uso de moneda y por tanto más frecuente será la pérdida.

A su vez, el planteamiento de Bost puede perfilarse aún más en el siguiente planteamiento: a mayor producción, mayor generación de excedentes, comercio de éstos, conexión con áreas comerciales a través de vías de comunicación e intercambio y uso de la moneda. Esta concatenación lógica no solo debió darse en las principales villae como propone Bost, sino que a nuestro juicio también debió generarse en las villae más pequeñas, a una menor escala y no dejando por tanto un registro arqueológico tan amplio como en las anteriores, ya que no dejaban de ser centros de producción y venta (Arce 2006: 14).

Por su parte, a mayor importancia de la vía cercana a la villa, mayor posibilidad de intercambios, y por tanto, mayor flujo monetario, explicando ello la amplia cantidad de cecas documentadas en los últimos momentos de la villa de Clavellinas, al igual que en cualquier otra de las mismas características y de situación similar. Su ubicación no solo le permitió nutrirse de los productos traídos de Augusta Emerita, sino también de otros procedentes de la Bética como salazones o cerámicas (Pastor 2002), fruto de la conexión viaria.

Este hecho se observa en otras villae cercanas, donde se identifican registros cerámicos muy similares, con la ventaja de que los restos cerámicos han sido estudiados y conectados con diferentes centros productivos. Nos referimos por ejemplo a la villa de Quinta das Longas en Élvas (Portugal), donde todos los productos cerámicos importados están condicionados por la situación privilegiada de esta villa, es decir, en el cruce de vías que conectaban la ciudad de Augusta Emerita con Olissipo (De Almeida y Carvalho 2002), pudiéndose identificar un gran número de terra sigillata de distintas épocas y sobre todo ánforas vinarias, olearias y de salazón procedentes de la zona atlántica y bética, donde también la Vía de la Plata tuvo su protagonismo. Esta dinámica ha sido también identificada, en cierta medida, en otros ejemplos situados en varios puntos de la actual Extremadura como son la de Los Términos en Monroy (Cáceres) (Herrera et al. 1991) y La Cocosa (Serra 1952), La Sevillana (Aguilar y Guichard 1995), Torre Águila (Rodríguez Martín 1993) y Las Motas (Sauceda 2006; Gibello y Sacudeda 2008), todas en la provincia de Badajoz.

La relación entre moneda, productos importados y $v i$ llae es muy remarcada por parte de Bost, quien compone varios cuadros comparativos entre el número de moneda encontrada y proporciones de cerámica importada registrada en diferentes villae hispanas. Premisa que muchos años después fue matizada por Cepeda (2000: 170) al identificar en las rutas de la circulación de moneda del s. IV, las rutas de distribución y comercialización de la cerámica fina de mesa de origen africano. En el registro arqueológico, se ha podido observar la convivencia de terra sigillata africana del tipo A, C y D que presentan cronologías de entre el s. III al $\mathrm{V}$ con un gran número monedas acuñadas desde mediados del s. III hasta finales del s. IV, no registrándose monedas a partir de estas fechas, debido a la involución económica que sufren algunos territorios interiores de la Lusitania hacia formas económicas donde la moneda tuvo un escaso papel (Cepeda 2000: 175).

De todas formas, la moneda es sinónimo de comercio y de transacción, por lo que es una evidencia clara de que se está produciendo dicha actividad. Una mayor presencia de numerario en época bajo imperial, como hemos documentado en esta villa, no solo es testimonio de un aumento de la masa circulante por la inflación como ya hemos señalado, sino también testimonio de un incremento de las transacciones comerciales como se ha podido observar en la presencia de importaciones y por el crecimiento de la producción de vino y aceite en la Lusitania en estas mismas fechas (Carvalho 1999; Cordero 2010; Rodríguez Martín 2011-12; Peña 2010: 192), atestiguado por las reformas generales en las respectivas bodegas y lagares de las villae lusitanas, documentadas también en el sector 1000 de nuestra villa. Este desarrollo de la producción vinícola y olearia coincide con la consolidación del poblamiento rural lusitano en torno a la mitad del s. III (Cerrillo y Fernández Corrales 1981), al igual que en el resto de la Península, donde se observa una continuidad de los siglos anteriores (Chavarria 2007: 78-79). 
Tampoco podemos olvidar la cercanía de este yacimiento a la ciudad de Augusta Emerita, sin duda, los flujos monetarios distribuidos desde la ciudad no pasarían desadvertidos para nuestra villa, como sucede con las cerámicas producidas en la ciudad y redistribuidas por ésta, como hemos podido observar en las terra sigillata y paredes finas. Reconrdamos que ya se advirtió en su día que las villae, como centro productivo, acaban siendo los principales suministradores de productos de primera necesidad a la ciudad (Álvarez Martínez 1983: 19; Arce 2006: 14; Fernández et al. 2014: 114; Peña 2010: 192).

Es evidente que la conexión de nuestro enclave con la Vía de la Plata condicionó su desarrollo económico y, sobre todo, su devenir, pues está claro que cuando los flujos comerciales desaparecieron, también lo hizo nuestra villa, al igual que les sucedió a otros ejemplos cercanos y ya referidos como Quinta das Longas (De Almeida y Carvalho 2002), La Cocosa (Serra 1952), Torre Águila (Rodríguez Martín 1993), Las Motas (Sauceda 2006; Gibello y Sacudeda 2008), La Sevillana (Aguilar y Guichard 1995) y los Términos (Cerrillo et al. 1991), que también estuvieron influenciados por vías de comunicación importantes y donde hemos observado las mismas evidencias productivas, presencia de importaciones y aparición de un numerario con cronología similar al catalogado por nosotros.

Por tanto, y atendiendo a todo lo anterior concluimos que la villa de Clavellinas es un centro productivo y residencial que surge en los años siguientes de la fundación de Augusta Emerita, que presenta una situación cercana a la Vía de la Plata. Su desarrollo se verá influido por los diferentes flujos comerciales que se desarrollen por este trazado viario, teniendo nuestro yacimiento una vida desde el s. I d.C. a mediados del V d.C., como así demuestran sus estructuras, las cerámicas y monedas documentadas. Esto concuerda perfectamente con la definición de villa abierta al comercio o practicante de una economía comercial definida por Bost, aunque como ya hemos comentado, su definición puede aplicarse a cualquier villa hispana que generara un mínimo de excedentes dignos de ser puestos en venta (Arce 2006: 14).

Noé Conejo Delgado Departamento de Prehistoria y Arqueología Universidad de Sevilla ccvdenoe@hotmail.com

\section{CATÁlogo}

Debido a que el registro monetario aportado por la villa romana de Clavellinas es bastante amplio, hemos optado por realizar su catálogo resumido en la siguiente tabla. Es cierto que en ella no se han recogido datos relativos a las leyendas y tipos de los anversos y reversos, pero han sido referidos en el comentario numismático que se ha realizando en puntos anteriores.

La tabla está compuesta por diez campos bastante simples y convencionales, pero explicamos a continuación las diferentes abreviaturas que se pueden encontrar en ella. En primer lugar tenemos que decir que la numeración que aportamos en el catálogo ha sido generada una vez se ha llevado a cabo una ordenación cronológica de todo el conjunto, siendo el que se encuentra entre paréntesis el número de referencia generado por el Museo Arqueológico Provincial de Badajoz cuando las piezas fueron depositadas tras la excavación. El siguiente campo (M.) hace referencia al tipo de metal en el que está acuñada la moneda, utilizando los convencionalismos AE para el bronce y AR para la plata, denario y antonininano en nuestro caso. El campo Val. alude a los valores monetales. Aquí también hemos optado por utilizar abreviaturas debido al espacio del que disponíamos en la tabla (Sest.: Sestercio; D: Denario; Ant : Antoniniano; Rad. Post. Ref.: Radiado Post Reforma; Foll.: Follis; Num: Nummus). El peso está expresado de manera convencional, en gramos con dos dígitos, el Mod. (módulo) en milímetros y el Eje (eje de cuños) en horas.

Tanto los nombres de emperador o ceca que aparecen seguidos de un signo de interrogación expresan nuestras dudas con respecto a la catalogación.

El campo llamado Cron. recoge la cronología estimada de cada moneda, que a su vez es la misma que aporta la referencia catalográfica contenida en el campo RIC, siglas del Roman Imperial Coinage, el catálogo de referencia que hemos utilizado para identificar, datar y catalogar nuestras monedas. La cita hace alusión al volumen correspondiente, número de pieza y página pertinente. El desglose bibliográfico de cada volumen se encuentra en la Bibliografía.

Por último, las monedas de las que no hemos podido extraer datos suficientes para su perfecta catalogación son citadas por el tipo monetal de su reverso. Las piezas señaladas con un asterisco (*) son de las que no hemos aportado reproducción gráfica, ya que su estado de 
conservación solo nos ha permitido poder catalogarlas, pues era bastante complicado poder fotografiarlas. Por lo que respecta a las demás, se ha intentado fotografiarlas de la mejor manera posible, pues a pesar de haber sido restauradas, en algunas ocasiones las leyendas y los tipos se encuentran muy desgastados complicando su reproducción, pero no ha impedido su identificación y catalogación.

\begin{tabular}{|c|c|c|c|c|c|c|c|c|c|}
\hline $\mathbf{N}^{0}$ & M. & Val. & Peso & Md & Eje & Emperador & Ceca & Cron. & $R / C$ \\
\hline $\begin{array}{l}1 \\
-6853\end{array}$ & $\mathrm{AE}$ & As & 7,57 & 25 & 5 & Augusto & Roma & 16 a.C. & t. I n 376, p. 70 \\
\hline $\begin{array}{l}2 \\
-6835\end{array}$ & $\mathrm{AE}$ & As & 12,6 & 29 & 7 & Claudio & Hispania? & 41 & t. I n 100 , p. 128 \\
\hline $\begin{array}{l}3 \\
-6866\end{array}$ & $\mathrm{AE}$ & As & 7,29 & 25 & -- & Claudio & Hispania? & $41-54$ & Rev. Frustro \\
\hline $\begin{array}{l}* \\
-6862\end{array}$ & $\mathrm{AE}$ & As & 9,95 & 29 & - & Claudio & Hispania? & $41-54$ & Rev. Frustro \\
\hline $\begin{array}{l}5 \\
-6860\end{array}$ & $\mathrm{AE}$ & As & 9,82 & 22 & -- & Vespasiano & Roma? & $69-79$ & Rev. Frustro \\
\hline $\begin{array}{l}6^{*} \\
-6870\end{array}$ & $\mathrm{AE}$ & As & 9,9 & 27 & 9 & Vespasiano & Roma? & $68-79$ & Rev. Frustro \\
\hline $\begin{array}{l}7 \\
-6882\end{array}$ & $\mathrm{AE}$ & Sest & 23,8 & 34 & 7 & Vespasiano & Lugdunum & 70 & t. II n 400, p. 64 \\
\hline $\begin{array}{l}8 \\
-6871\end{array}$ & AR & $\mathrm{D}$ & 3.09 & 17 & 11 & Vespasiano & Roma & 71 & t. Il n 39, p. 19 \\
\hline $\begin{array}{l}9 \\
-6894\end{array}$ & $A \mathrm{E}$ & Sest & 22,5 & 33 & 5 & Domiciano & Roma & 81 & t. II $n^{\circ} 234$, p. 183 \\
\hline \begin{tabular}{|l|}
10 \\
-6872 \\
\end{tabular} & AE & As & 11,6 & 27 & 5 & Adriano & Roma? & $117-138$ & No clasificable \\
\hline \begin{tabular}{|l|}
11 \\
-6873
\end{tabular} & $\mathrm{AE}$ & Sest & 27,1 & 39 & 10 & Adriano & Roma? & $117-138$ & No clasificable \\
\hline $\begin{array}{l}12 \\
-6856\end{array}$ & $\mathrm{AE}$ & Sest & 25,3 & 33 & 4 & Adriano & Roma & $126-128$ & t. II n 637, p. 424 \\
\hline $\begin{array}{l}13 \\
-6844\end{array}$ & AR & Ant & 2,22 & 22 & 7 & Galieno & Roma & $253-268$ & t. $\mathrm{V}-1 \mathrm{n}^{\mathrm{o}} 317$, p. 158 \\
\hline $\begin{array}{l}14 \\
-6891\end{array}$ & AR & Ant. & 1,77 & 18 & 6 & Galieno & Mediolanum & 257 & $\begin{array}{l}\text { t. V-1 n } 373 \text {, var. p. } \\
98\end{array}$ \\
\hline $\begin{array}{l}15 \\
-6901\end{array}$ & AR & Ant & 3,12 & 18 & 10 & Galieno & Roma & 267 & t. V-l n"179, p. 146 \\
\hline $\begin{array}{l}16 \\
-6850\end{array}$ & AR & Ant. & 1,76 & 14 & 7 & Aureliano (Divo Claudio) & Imitación & 270 & t.V-1 n 261, p. 233 \\
\hline $\begin{array}{l}17 \\
-6864\end{array}$ & AR & Ant. & 1,93 & 16 & 5 & Aureliano (Divo Claudio) & Imitación & 270 & t. $V-1$ n $^{\circ} 261$, p. 233 \\
\hline \begin{tabular}{|l|}
18 \\
-6893 \\
\end{tabular} & AR & Ant. & 1,76 & 16 & 7 & Aureliano (Divo Claudio) & Imitación & 270 & t.V-1 n 261, p. 233 \\
\hline $\begin{array}{l}19 \\
-6833\end{array}$ & AR & Ant. & 2,08 & 19 & 8 & Aureliano (Divo Claudio) & Imitación & 270 & t.V-1 n 261, p. 233 \\
\hline $\begin{array}{l}20 \\
-6897\end{array}$ & $\mathrm{AE}$ & $\begin{array}{l}\text { Rad. post. } \\
\text { Ref. }\end{array}$ & 2,58 & 23 & 5 & Galerio & Carthago & 303 & t.VI n 35 b, p. 427 \\
\hline
\end{tabular}


Noé Conejo Delgado

\begin{tabular}{|c|c|c|c|c|c|c|c|c|c|}
\hline $\mathbf{N}^{\circ}$ & M. & VaI. & Peso & Md & Eje & Emperador & Ceca & Cron. & $R I C$ \\
\hline $\begin{array}{l}21 \\
-6888\end{array}$ & $\mathrm{AE}$ & Foll. & 6,68 & 25 & 6 & Constantino & Londinum & $307-310$ & t.VI n 108, p. 132 \\
\hline $\begin{array}{l}22 \\
-6869\end{array}$ & $\mathrm{AE}$ & Foll. & 6,7 & 25 & 6 & Majencio & Ostia & 309 & t.VI no 14, p. 403 \\
\hline $\begin{array}{l}23 \\
-6863\end{array}$ & $\mathrm{AE}$ & Foll. & 3,43 & 22 & 11 & Constantino & Arelate & $315-316$ & t.VII n $^{\circ} 57$, p. 238 \\
\hline $\begin{array}{l}24 \\
-6896\end{array}$ & AE & Foll. & 3,03 & 19 & 6 & Constantino & Treveris & $322-323$ & t.VII no 363, p. 197 \\
\hline $\begin{array}{l}25 \\
-6841\end{array}$ & $\mathrm{AE}$ & Foll. & 2,48 & 18 & 3 & Constantino & Ticinum & 320 & t. VII $n^{\circ} 131, p .378$ \\
\hline $\begin{array}{l}26 \\
-6861\end{array}$ & $\mathrm{AE}$ & Foll. & 2,82 & 18 & 5 & Constantino II & Treveris & 324- 325 & t. VII n 455 , p. 205 \\
\hline $\begin{array}{l}27 \\
-6825\end{array}$ & $\mathrm{AE}$ & Num & 2,25 & 17 & 3 & Urbs Roma & Arelate & $330-340$ & t. VII n' 373, p. 274 \\
\hline $\begin{array}{l}28 \\
-6858\end{array}$ & $\mathrm{AE}$ & Num & 1,11 & 14 & 2 & Urbs Roma & Lugdunum & $330-331$ & t. VII n 242, p. 138 \\
\hline $\begin{array}{l}29 \\
-6877\end{array}$ & $\mathrm{AE}$ & Num & 2,46 & 17 & 5 & Constantino II & Constantinopolis & $330-331$ & t. VII n 60, p. 579 \\
\hline $\begin{array}{l}30 \\
-6885\end{array}$ & $\mathrm{AE}$ & Num & 1,81 & 15 & 6 & Constantino II & Lugdhmum & 332 & t. VII n ${ }^{\circ} 243$, p. 138 \\
\hline $\begin{array}{l}31 \\
-6827\end{array}$ & $\mathrm{AE}$ & Num & 1,93 & 17 & 6 & Constantino II & -- & $330-333$ & Tipo Gloria Exercitus \\
\hline $\begin{array}{l}32 \\
-6831\end{array}$ & $\mathrm{AE}$ & Num & 1,38 & 15 & 6 & Constantino II? & -- & $330-333$ & Tipo Gloria Exercitus \\
\hline $\begin{array}{l}33 \\
-6887\end{array}$ & $\mathrm{AE}$ & Num & 1,28 & 13 & 9 & Dinastía Constantiniana & Heraclea & $337-340$ & t. VII n' 14, p. 431 \\
\hline $\begin{array}{l}34 \\
-6832\end{array}$ & $\mathrm{AE}$ & Num & 1,28 & 15 & 6 & Constante & Siscia & $337-347$ & t. VIII n' 78, p. 354 \\
\hline $\begin{array}{l}35 \\
-6879\end{array}$ & $\mathrm{AE}$ & Num & 1,29 & 15 & 7 & Constante & Arelate & $340-350$ & t. VIII nº 58, p. 206 \\
\hline $\begin{array}{l}36 \\
-6852\end{array}$ & $\mathrm{AE}$ & Num & 1,11 & 15 & 4 & Constante & Roma & Post. 340 & t. VIII nº $26, p \cdot 250$ \\
\hline $\begin{array}{l}37 \\
-6856\end{array}$ & $\mathrm{AE}$ & Num & 1,5 & 15 & 10 & Constante & Roma & $347-348$ & t. VIII n' 183, p. 263 \\
\hline $\begin{array}{l}38 \\
-6879\end{array}$ & AE & Num & 1,91 & 15 & 12 & Constante & -- & $337-347$ & Tipo Gloria Exercitus \\
\hline $\begin{array}{l}39 \\
-6849\end{array}$ & $\mathrm{AE}$ & Num & 1,85 & 10 & 8 & Constancio II & Nicomedia & $348-351$ & t. VIII no 69, p. 475 \\
\hline $\begin{array}{l}40 \\
-6880\end{array}$ & $\mathrm{AE}$ & AE3 & 1,71 & 15 & 5 & Decencio & Arelate & $350-353$ & t. VIII n 182, p. 216 \\
\hline $\begin{array}{l}41 \\
-6848\end{array}$ & AE & AE2 & 4,41 & 24 & 7 & Decencio & Roma & $351-353$ & t. VIII no 208, p. 267 \\
\hline $\begin{array}{l}42 \\
-6857\end{array}$ & $\mathrm{AE}$ & AE3 & 1,96 & 18 & 9 & Constancio II & Constantinopolis & $352-355$ & t. VIII $n^{\circ} 126$, p. 458 \\
\hline $\begin{array}{l}43 \\
-6838\end{array}$ & AE & AE4 & 2,01 & 16 & 7 & Constancio II & Arelate & $355-360$ & t. VIII n 275, p. 224 \\
\hline $\begin{array}{l}44 \\
-6874\end{array}$ & $\mathrm{AE}$ & AE2 & 4,1 & 16 & 3 & Constancio II & Siscia & $355-360$ & t. VIII n 377, p. 377 \\
\hline $\begin{array}{l}45 \\
-6838\end{array}$ & $\mathrm{AE}$ & AE3 & 2,01 & 10 & 12 & Constancio II & -- & $355-360$ & $\begin{array}{l}\text { Tipo Fel. Temp. } \\
\text { Reparatio }\end{array}$ \\
\hline
\end{tabular}




\begin{tabular}{|c|c|c|c|c|c|c|c|c|c|}
\hline $\mathbf{N}^{0}$ & M. & Val. & Peso & Md & Eje & Emperador & Ceca & Cron. & $R I C$ \\
\hline $\begin{array}{l}46 \\
-6898\end{array}$ & $\mathrm{AE}$ & AE3 & 1,75 & 17 & 3 & Constancio II & -- & $355-360$ & $\begin{array}{l}\text { Tipo Fel. Temp. } \\
\text { Reparatio }\end{array}$ \\
\hline $\begin{array}{l}47^{*} \\
-6840\end{array}$ & $\mathrm{AE}$ & $\mathrm{AE} 4$ & 1,36 & 14 & 4 & Constancio II & -- & $355-360$ & $\begin{array}{l}\text { Tipo Spes Rei } \\
\text { Pvplicae }\end{array}$ \\
\hline $\begin{array}{l}48 \\
-6843\end{array}$ & $\mathrm{AE}$ & AE3 & 2,19 & 18 & 6 & Constancio II & -- & $355-360$ & $\begin{array}{l}\text { Tipo Fel. Temp. } \\
\text { Reparatio }\end{array}$ \\
\hline $\begin{array}{l}49 \\
-6895\end{array}$ & $\mathrm{AE}$ & AE3 & 2,22 & 14 & 7 & Constancio II & -- & $355-360$ & $\begin{array}{l}\text { Tipo Fel. Temp. } \\
\text { Reparatio }\end{array}$ \\
\hline $\begin{array}{l}50 \\
-6875\end{array}$ & $\mathrm{AE}$ & $\mathrm{AE} 4$ & 1,75 & 15 & 3 & Constancio II & -- & $355-360$ & $\begin{array}{l}\text { Tipo Fel. Temp. } \\
\text { Reparatio }\end{array}$ \\
\hline $\begin{array}{l}51 \\
-6890\end{array}$ & $\mathrm{AE}$ & $\mathrm{AE} 4$ & 2,35 & 17 & 3 & Constancio II & -- & $355-360$ & $\begin{array}{l}\text { Tipo Fel. Temp. } \\
\text { Reparatio }\end{array}$ \\
\hline $\begin{array}{l}52 \\
-6855\end{array}$ & $\mathrm{AE}$ & $\mathrm{AE} 4$ & 2,11 & 19 & 5 & Constancio II & -- & $355-360$ & $\begin{array}{l}\text { Tipo Fel. Temp. } \\
\text { Reparatio }\end{array}$ \\
\hline $\begin{array}{l}53 \\
-6892\end{array}$ & AE & AE4 & 2,19 & 18 & 6 & Constancio II? & -- & $355-360$ & $\begin{array}{l}\text { Tipo Fel. Temp. } \\
\text { Reparatio }\end{array}$ \\
\hline $\begin{array}{l}54 \\
-6889\end{array}$ & $\mathrm{AE}$ & AE3 & 1,63 & 20 & 5 & Constancio II? & -- & $355-360$ & $\begin{array}{l}\text { Tipo Fel. Temp. } \\
\text { Reparatio }\end{array}$ \\
\hline $\begin{array}{l}55 * \\
-6827\end{array}$ & $\mathrm{AE}$ & AE3 & 2,02 & 17 & 3 & Juliano II & -- & $355-360$ & $\begin{array}{l}\text { Tipo Fel Temp } \\
\text { Reparatio }\end{array}$ \\
\hline $\begin{array}{l}56 \\
-6857\end{array}$ & $\mathrm{AE}$ & $\mathrm{AE} 2$ & 5,48 & 22 & 6 & Graciano & Constantinopolis & $375-383$ & t. IX nº $54 a$, p. 226 \\
\hline $\begin{array}{l}57 \\
-6887\end{array}$ & $\mathrm{AE}$ & AE2 & 4,61 & 22 & 7 & Graciano & -- & $375-383$ & Tipo Reparatio Reipub \\
\hline $\begin{array}{l}58 * \\
-6847 \\
\end{array}$ & $\mathrm{AE}$ & AE2 & 4,6 & 21 & 12 & Graciano & -- & $375-383$ & Tipo Reparatio Reipub \\
\hline $\begin{array}{l}59 \\
-6851\end{array}$ & $\mathrm{AE}$ & AE2 & 4,27 & 21 & 6 & Graciano & Aquileia & $378-383$ & t. IX $\mathbf{n}^{\circ} 30 \mathrm{a}$, p. 100 \\
\hline $\begin{array}{l}60 \\
-6867\end{array}$ & $\mathrm{AE}$ & AE2 & 4,84 & 20 & 2 & Graciano & Lugdunum & $378-383$ & t. $\mathrm{IX} \mathrm{n}^{\circ} 28 \mathrm{a}, \mathrm{p} .48$ \\
\hline $\begin{array}{l}61 \\
-6878\end{array}$ & $\mathrm{AE}$ & $\mathrm{AE} 2$ & 4,67 & 25 & 1 & Valentiniano II & Constantinopolis & $378-383$ & t. IX no $54 b$, p. 226 \\
\hline $\begin{array}{l}62 \\
-6868\end{array}$ & $\mathrm{AE}$ & AE2 & 3,54 & 22 & 5 & Valentiniano II & Constantinopolis & $378-383$ & t. IX n' $54 b$, p. 226 \\
\hline $\begin{array}{l}63 \\
-6876\end{array}$ & $\mathrm{AE}$ & $\mathrm{AE} 2$ & 4,75 & 21 & 10 & Teodosio I & Nicomedia & $378-383$ & t. IX nº 27 var. p, 257 \\
\hline $\begin{array}{l}64 * \\
-6842\end{array}$ & AE & AE2 & 4,42 & 21 & 4 & Teodosio I & Constantinopolis & $392-395$ & t. IX nº 88 a, p. 235 \\
\hline $\begin{array}{l}65 \\
-6834\end{array}$ & $\mathrm{AE}$ & AE2 & 4,42 & 21 & 10 & Teodosio I & Antioquia & $392-395$ & t. IX nº 68a p. 294 \\
\hline $\begin{array}{l}66 \\
-6836\end{array}$ & $\mathrm{AE}$ & $\mathrm{AE} 2$ & 4,83 & 20 & 6 & Arcadio & Constantinopolis & $392-395$ & t. IX n' 88 a, p. 235 \\
\hline $\begin{array}{l}67 \\
-6881\end{array}$ & $\mathrm{AE}$ & AE2 & 3,04 & 22 & 9 & Frustro & Siscia & ¿? & Tipo Reparatio Reipub \\
\hline $\begin{array}{l}68 \\
-6865\end{array}$ & $\mathrm{AE}$ & As & 8,15 & 27 & -- & Frustro & Frustro & ss. I-II- & -- \\
\hline $\begin{array}{l}69 \\
-6829\end{array}$ & $\mathrm{AE}$ & $\mathrm{AE} 4$ & 1,19 & 12 & -- & Frustro & - & s. IV & .. \\
\hline $\begin{array}{l}70 \\
-6830\end{array}$ & $\mathrm{Fe}$ & -- & 6,76 & 25 & -- & Disco & -- & -- & -- \\
\hline
\end{tabular}




\section{BIBLIOGRAFÍA}

AGUILAR, A.; GUICHARD, P. (1995): La ciudad antigua de Lacimurga y su entorno rural, Badajoz.

ALONSO, A.; CERRILLO, E.; FERNÁNDEZ, J. M. (1992-93): Tres ejemplos de poblamiento rural romano en torno a ciudades de la Vía de la Plata: Augusta Emerita, Norba Caesarina y Capara, Stvdia Historica Historia Antigua X- XI, 67-87.

ÁLVAREZ MARTÍNEZ, J. M. (1983): El puente romano de Mérida, Badajoz.

ARCE, J. (2006): Villae en el paisaje rural de Hispania romana durante la Antigüedad tardía, Villas Tardoantiguas en el Mediterráneo Occidental (A. Chavarría, J. Arce, y G.P. Brogiolo, eds.), Anejos de AEspA XXXIX, 9-16.

ARIAS, L. (2012): Hispania en el siglo II d.C.: circulación y perduración de la moneda, BAR i.s. S2327, Oxford.

ARIÑO, E.; GURT, J. M.; PALET, J. M. (2004): El pasado presente. Arqueología de los paisajes en la Hispania Romana, Salamanca.

BLANCO, J.F. (1987): Moneda y circulación monetaria en Coca (siglos II a.C.-V d.C.), Segovia.

BLAZQUEZ CERRATO, M. C. (2002): La circulación monetaria en el área occidental de la Península Ibérica. La moneda en torno al Camino de la Plata, Montagnac.

BOST, J. P. (1992-93): Villa y circulación monetaria: Hipótesis de trabajo, Stvdia Historica. Historia Antigua X-XI, 219-225.

CAMPO, M. (1990): Las monedas de la villa romana de La Olmeda, Palencia.

CARSON, R. A. G.; KENT, J. P. C. (1976): Bronce roman imperial coinage of the Later Empire (Part. II), London.

CARVALHO, A. (1999): Evidências arqueológicas da produçào de vino nas villae romanas do territorio portugês: graíhas de uva, alfaias vitícolas e lagares de vino, Économie et territoire en Lusitanie romaine (J. G. Gorges y F.G. Rodríguez Martín Eds.), Madrid, 361-390.

CHAVARRÍA, A. (2006): Villas en Hispania durante la Antigüiedad Tardía, Villas Tardoantiguas en el Mediterráneo Occidental (A. Chavarría, J. Arce, y G. P. Brogiolo, eds.), Anejos de AEspA XXXIX, 17-36.

CHAVARRÍA, A. (2007): El final de las villae en Hispania (siglos IV-VIII), Turnhout, Belgium.

CEPEDA, J. J. (2000): Maiorina Gloria Romanorum. Monedas, tesoros y áreas de circulación en Hispania en el tránsito del siglo IV al siglo V, AEspA 181-182, 16-192.

CERRILlO, E. (1984): La vida rural romana en Extremadura, Cáceres.

CERRILLO, E.; FERNÁNDEZ, J. M. (1981): Un ejemplo de relación campo ciudad. La distribución espacial de los mosaicos de la Lusitania, Norba II, 153-164.

CORDERO, T. (2011): El territorio emeritense durante la Antigüedad tardía, Actas Congreso Internacional 1910 - 2010 El Yacimiento Emeritense (J. M. Álvarez Martínez y P. Mateos, eds.), Mérida, 547-561.
DA SILVA RUIVO, J. (2008): Circulaçâo monetária na Lusitânia do século III. (Vol. I y II). Tesis doctoral inédita. Universidade do Porto.

DE ALMEIDA, M. J.; CARVALHO, A. (2002): Vía e Circulação do produtos no SW do conventus emeritensis: o exemplo da Quinta das Longas (Elvas), V Mesa Redonda Internacional sobre Lusitania Romana: Las comunicaciones (J. Georges, E. Cerrillo y T. Nogales, eds.), Cáceres, 369-390.

FERNÁNDEZ DE CASTRO, M. C. (1982): Villas romanas en Hispania, Madrid.

FERNÁNDEZ OCHOA, C.; SALIDO, J.; ZARZALEJOS, M. (2014): Las formas de ocupación rural en Hispania. Entre la terminología y la praxis arqueológica, CUPAUAM 40, 111-136.

FIGUEROLA, M. (1999): La circulación del Ae2 teodosiano en la vía de la Plata, Rutas, Ciudades y monedas en Hispania: actas del II Encuentro Peninsular de Numismática Antigua, Porto, marzo 1997 (M. Mora, R. M. Sobral y M. P. García-Bellido, coords), Madrid, 367-380.

GUIBELLO, V.; SAUCEDA, S. (2008): Las Motas: aproximación arqueológica a un asentamiento desaparecido, VIII Jornada de Historia de Fuente de Cantos (V. M. Guibello, coord.), 9-42.

GURT, J. M. (1985): Clunia III. Hallazgos monetarios, Madrid.

HERRERA, G.; CASTILLO, J.; HERNÁNDEZ LÓPEZ, M.; ALVARADO, M.; MOLANO, J.; CERRILLO, E. (1991): Excavaciones arqueológicas en la villa romana de Los Términos, Monroy (Cáceres). Actuaciones y propuestas de futuro (1884-1990), Extremadura Arqueológica II, 95-128.

JURADO, G.; TIRAPU, L. M. (2002): Informe memoria arqueológica del yacimiento las clavellinas. TM. de Torremegia. En las obras de la Autovía Ruta de la Plata. Tramo MéridaAlmendralejo-Sur (Pk-16+480 al Pk 16+660), Arquepec. S. L, depositado en la Dirección General de Patrimonio de Patrimonio Cultural de la Consejería de Educación y Cultura del Gobierno de Extremadura, Mérida.

JURADO, G.; TIRAPU, L. M. (2006): Excavación arqueológica del yacimiento "Las Clavellinas", Extremadura Arqueológica X, 233-354.

MÍNGUEZ MORALES, J. A. (2005): La cerámica de paredes finas, Introducción al Estudio de la Cerámica Romana. Una breve guía de referencia (M. Roca y M. I. Fernández García, coords.), Málaga, 317-404.

PASTOR, M. (2012): Vías de comunicación y relaciones comerciales entre Betica y Lusitania, V Mesa Redonda Internacional sobre Lusitania Romana: Las comunicaciones (J. Georges, E. Cerrillo y T. Nogales, eds.) Cáceres, 195-222.

PEÑA, Y. (2010): Torcularia. La producción de vino y aceite en Hispania, Tarragona.

PEREIRA, M. I. S.; BOST, J. P.; HIERNARD, J. (1974): Fouilles de Conimbriga III. Les monnaies, Paris.

RIC I: SUTHERLAND, C. H. V. (1923): Roman Imperial Coinage, from Augustus to Vitellius, London. 
RIC II: MATTINGLY, H.; SYDENHAM, E. A. (1926): Roman Imperial Coinage, from Vespasian to Hadrian, London.

RIC V-1: WEBB, P.H. (1933): Roman Imperial Coinage, from Valerian to Florian, London.

RIC VI: SUTHERLAND, C. H. V. (1967): Roman Imperial Coinage, from the Diocletian Reform to Maximinus II, London.

RIC VII: BRUUN, P. M. (1966): Roman Imperial Coinage, from Constantine I to Licinius, London.

RIC VIII: KENT, J. P. C. (1981): Roman Imperial Coinage: The Family of Constantine I, London.

RIC IX: MATTINGLY, H.; SUTHERLAND, C. H. V.; LITT, D.; CARSON, R. A. G. (1951): Roman Imperial Coinage, from Valentinian I to Theodosius I, London.

RIPOLLÈS, P. P. (2002): La moneda romana imperial y su circulación en Hispania, AEspA 185-186, 195-214.

RODRÍGUEZ CASANOVA, I. (2002): La circulación monetaria antigua en los valles de Benavente (Zamora), Benavente.

RODRÍGUEZ MARTÍN, F. G. (1993): La villa romana de Torre del Águila, Barbaño (Badajoz), Tesis Doctoral Inédita. Universidad de Extremadura.

RODRÍGUEZ MARTÍN, F. G. (2011-2012): La producción de vino y aceite entre Augusta Emérita y el occidente atlántico, Anales de Prehistoria y Arqueología 27-28, 451-469.

RODRÍGUEZ MARTÍN, F. G. (2008-2009): Las vías romanas de Lusitania: el trazado en el Conventus Emeritense y su proyección hacia la fachada atlántica, Anas 21-22, 415-469.

RODRÍGUEZ VIDA, J; VILLALOBOS, M.; JORQUERA, A.; DÍAZ DEL OLMO, F. (1988): Geomorfología del sector meridional de la cuenca del Guadiana, Revista de la Sociedad Geológica de España 1 (1 -2), 157-164.

ROLDÁN, J. M. (1971): Iter ab Emerita Asturicam. El camino de la Plata, Salamanca.
ROMERO, M. V.; RUIZ MONTES, P. (2005): Los centros de producción de T.H.S. en la zona septentrional de la Península Ibérica, Introducción al Estudio de la Cerámica Romana. Una breve guía de referencia (M. Roca y M. I. Fernández García, coords.), Málaga, 183-224.

SÁEZ PRECIADO M. P.; SÁEZ PRECIADO, C., (1999): Estado de la cuestión de las alfares riojanos. La terra sigillata hispánica altoimperial, Terra Sigillata Hispánica. Centros de fabricación y producción alto imperiales. Homenaje a $M^{a}$. A. Mezquíriz (M. Mora y M. I. Fernández García, coords.), Jaén-Málaga, 61-136.

SÁNCHEZ BARRERO, P. D. (2000): Territorio y sociedad en Augusta Emerita, Sociedad y cultura en la Lusitania romana: IV Mesa Redonda Internacional (J. G. Gorges y T. Nogales Basarrate, coord.), Mérida, 203-228.

SÁNCHEZ BARRERO, P. D. (2011): El territorio periurbano emeritense: Un espacio situado entre la ciudad y el campo, Actas Congreso Internacional 1010-2010: El Yacimiento Emeritense, 2011 (J.M. Álvarez Martínez y P. Mateos Cruz, eds.), Mérida, 291-310.

SAN VICENTE, J. I. (1999): Circulación monetaria en Hispania durante el siglo IV d.C., Casa de la Moneda, Madrid.

SAN VICENTE, J. I. (2008): Perduración de la moneda romana durante el siglo IV en Hispania: años 294-348, Actas XIII Congreso Nacional de Numismática "Moneda y arqueología” (A. Arévalo González, coord.), Cádiz, 611-636.

SAUCEDA, S. (2006): Excavación arqueológica de "Las Motas", Extremadura Arqueológica X, 291-231.

SERRA RAFOLS, J. C. (1952): La villa romana de la dehesa de La Cocosa, Badajoz.

SMITH, J. T. (1997): Roman Villas. A study in social structure, London-New York. 